\title{
Results From the United States of America's 2016 Report Card on Physical Activity for Children and Youth
}

\author{
Peter T. Katzmarzyk, Kara D. Denstel, Kim Beals, Christopher Bolling, Carly Wright, \\ Scott E. Crouter, Thomas L. McKenzie, Russell R. Pate, Brian E. Saelens, \\ Amanda E. Staiano, Heidi I. Stanish, and Susan B. Sisson
}

\begin{abstract}
Background: The 2016 United States (U.S.) Report Card on Physical Activity for Children and Youth provides a comprehensive evaluation of physical activity levels and factors influencing physical activity among children and youth. Methods: The report card includes 10 indicators: Overall Physical Activity, Sedentary Behavior, Active Transportation, Organized Sport Participation, Active Play, Health-related Fitness, Family and Peers, School, Community and the Built Environment, and Government Strategies and Investments. Nationally representative data were used to evaluate the indicators using a standard grading rubric. Results: Sufficient data were available to assign grades to 7 of the indicators, and these ranged from $B$ - for Community and the Built Environment to $F$ for Active Transportation. Overall Physical Activity received a grade of $D$ - due to the low prevalence of meeting physical activity guidelines. A grade of $D$ was assigned to Health-related Fitness, reflecting the low prevalence of meeting cardiorespiratory fitness standards. Disparities across age, gender, racial/ethnic and socioeconomic groups were observed for several indicators. Conclusions: Continued poor grades suggest that additional work is required to provide opportunities for U.S. children to be physically active. The observed disparities indicate that special attention should be given to girls, minorities, and those from lower socioeconomic groups when implementing intervention strategies.
\end{abstract}

Keywords: adolescent, exercise, fitness, sedentary, surveillance

Physical inactivity remains a global health issue. It has been estimated that $6 \%$ to $10 \%$ of the cases of several major chronic diseases and $9 \%$ of premature mortality worldwide is attributable to physical inactivity. ${ }^{1}$ The current physical activity (PA) guidelines in the United States (U.S.) $)^{2}$ and globally ${ }^{3}$ call for children and youth to participate in at least 60 minutes of MVPA daily, including vigorous activities on at least 3 days per week. Muscle and bone strengthening activities should also be performed on at least 3 days of the week. However, approximately $80 \%$ of adolescents globally are not achieving the minimum recommended guidelines for moderate-tovigorous physical activity (MVPA). ${ }^{4}$ The U.S. follows the global trend, as it is estimated that only approximately $25 \%$ of children and youth participate in 60 minutes of daily MVPA. ${ }^{5,6}$

The primary goal of the 2016 United States Report Card on Physical Activity for Children and Youth is to assess and track levels of PA and sedentary behaviors in U.S. children and youth,

Katzmarzyk, Denstel, and Staiano are with Pennington Biomedical Research Center, Baton Rouge, LA. Beals is with the School of Health and Rehabilitation Sciences, University of Pittsburgh, Pittsburgh, PA. Bolling is with the American Academy of Pediatrics, Elk Grove Village, IL. Wright is with SHAPE America, Reston, VA. Crouter is with the Dept of Kinesiology, Recreation, and Sport Studies, The University of Tennessee, Knoxville, TN. McKenzie is with the School of Exercise and Nutritional Sciences, San Diego State University, San Diego, CA. Pate is with the Dept of Exercise Science, University of South Carolina, Columbia, SC. Saelens is with the Dept of Pediatrics, University of Washington, Seattle, WA. Stanish is with the Dept of Health and Exercise Sciences, University of Massachusetts, Boston. Sisson is with the Dept of Nutritional Sciences, University of Oklahoma Health Sciences Center, Oklahoma City, OK. Katzmarzyk (Peter.Katzmarzyk@pbrc.edu) is corresponding author. facilitators and barriers for PA, and related health outcomes. The 2016 U.S. Report Card was developed under the auspices of the National Physical Activity Plan Alliance (www.physicalactivityplan. org). This report summarizes the process and main results of the 2016 U.S. Report Card. The 2016 U.S. Report Card provides an update on the current status since the release of the inaugural 2014 U.S. Report Card. ${ }^{7}$

\section{Methods}

The 2016 U.S. Report Card was developed and produced by the U.S. Report Card Research Advisory Committee, which was established as a subcommittee of the National Physical Activity Plan Alliance (NPAPA). The Committee consisted of 12 volunteer members with a wide range of expertise in different aspects of PA among children and youth. The Committee was charged with identifying key data sources to inform the grading of the report card indicators, assigning grades to each indicator, and producing the final report card document (available at www.physicalactivityplan.org). The authors of the present report were members of the 2016 U.S. Report Card Research Advisory Committee.

The 2016 U.S. Report Card includes 10 indicators related to PA and the potential barriers and facilitators to being physically active. The indicators that were assessed are provided in Table 1. The Committee identified nationally representative sources of surveillance data to inform the grading of each indicator. The primary data sources included in the Report Card included the National Health and Nutrition Examination Survey (NHANES), Youth Risk Behavior Surveillance System (YRBSS), NHANES National Youth Fitness Survey (NNYFS), National Survey of Children's Health (NSCH), and the National Household Travel Survey (NHTS). 
Table 1 Grades According to Physical Activity Indicator in the 2016 United States Report Card on Physical Activity for Children and Youth

\begin{tabular}{lc}
\hline Indicator & Grades \\
\hline Overall Physical Activity Levels & $D-$ \\
Organized Sport Participation & $C-$ \\
Active Play & $I N C$ \\
Active Transportation & $F$ \\
Sedentary Behaviors & $D-$ \\
Family and Peers & $I N C$ \\
School & $D+$ \\
Health-related Fitness & $D$ \\
Community and the Built Environment & $B-$ \\
Government Strategies and Investments & $I N C$ \\
\hline
\end{tabular}

Note. The grade for each indicator is based on the percentage of children and youth meeting a defined benchmark: $A$ is $81 \%$ to $100 \% ; B$ is $61 \%$ to $80 \%$; $C$ is $41 \%$ to $60 \%, D$ is $21 \%$ to $40 \% ; F$ is $0 \%$ to $20 \%$; INC is Incomplete data.

Data from several additional surveys were used as secondary data sources to further inform the grade assignments and to provide information on the social and demographic context of PA, including its facilitators and barriers to participation. While the 2014 Report Card relied exclusively on published reports to inform the grading of the indicators, ${ }^{7}$ the 2016 Report Card includes the results of several original data analyses conducted by the Committee using publicly available datasets, as described below in relation to the results for each indicator.

Each of the 10 indicators in the 2016 Report Card was assigned a letter grade ( $A, B, C, D, F$, or $I N C$ [Incomplete]) using the rubric that was developed for the 2014 Report Card (see footnote of Table 1). ${ }^{7}$ A primary, nationally representative data source was used to assign a preliminary grade based on the grading rubric through a quantitative evaluation of the indicator and the primary data. Following the preliminary grade assignment, the Committee reviewed the primary data for sociodemographic disparities as well as several secondary data sources which provided further context, and if significant disparities were identified (eg, age, gender, race/ ethnicity, socioeconomic status), the grade was lowered to reflect the disparity. Depending on the severity of the observed disparities, the grades were lowered to either a minus grade or even a full lower letter grade based on the consensus of the Committee.

The 2016 Report Card was developed over a period of 1 year and involved several teleconferences and frequent e-mail communication among the Committee members. In addition, individual committee members were tasked with writing and reviewing specific sections of the report card to distribute the workload and capitalize on Committee members' expertise. Briefly, the major tasks of the Committee were accomplished during a series of teleconferences. The first teleconference was used to review the goals of the 2016 U.S. Report Card, identify which indicators to include in the 2016 U.S. Report Card, and identify the best sources of data to inform each grade. For consistency, the committee maintained the indicators from the 2014 Report Card and also attempted to maintain consistency with the primary data sources to the extent possible. The goal of the second series of teleconferences was to review the data that were compiled for each indicator and to assign the final grades. A final set of teleconferences was convened to review and approve the final report card documents, after incorporating all Committee members' comments on the draft documents.

\section{Results}

The 2016 U.S. Report Card (see Figure 1) represents the second comprehensive assessment of PA in U.S. children and youth under the auspices of the NPAPA, and follows the inaugural 2014 U.S. Report Card. ${ }^{7}$ Table 1 provides a list of the indicators assessed along with the associated grades assigned for 2016.

\section{Overall Physical Activity: D-}

The primary data source for overall PA levels among children and youth was the 2005-06 NHANES accelerometer dataset, which provides an objective assessment of PA. Although these data are several years old, this is the most recently available nationally representative

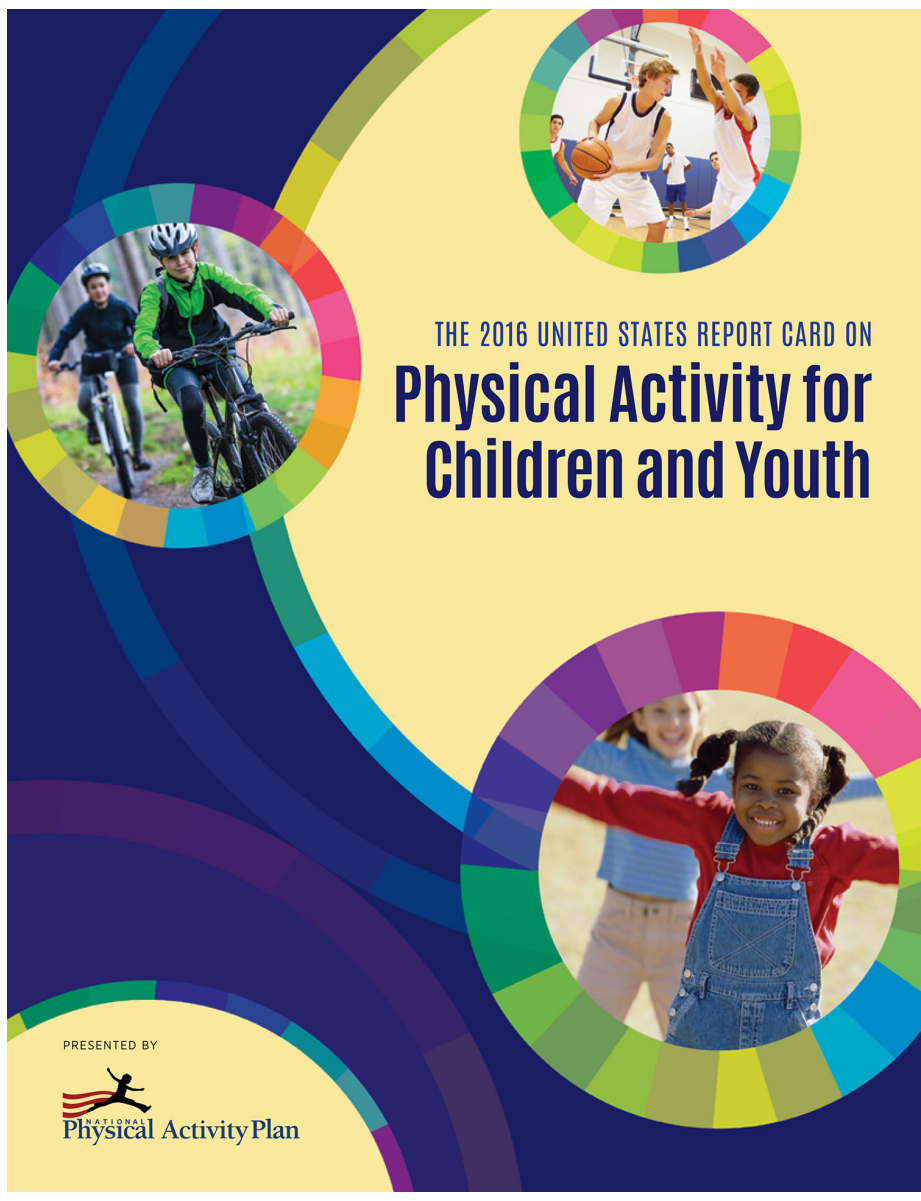

Figure 1 - Front cover of the 2016 United States Report Card on Physical Activity for Children and Youth. 
public data on this topic. The publically available NHANES dataset was used to estimate the prevalence of children meeting current PA guidelines ( $60 \mathrm{~min} /$ day $)^{2}$ on at least 5 of 7 days, using the Bayesian approach employed by Troiano and colleagues. ${ }^{5}$ Overall, $21.6 \%$ (95\% CI: $20.0 \%$ to $23.2 \%$ ) of 6- to 19 -year-old U.S. children met the guidelines, and more boys $(26.0 \% ; 23.9 \%$ to $28.2 \%)$ than girls $(16.9 \% ; 15.0 \%$ to $18.9 \%)$ were considered physically active. Further, PA levels higher in younger children compared with older youth, with $42.5 \%$ ( $40.1 \%$ to $44.9 \%$ ) of 6- to 11 -year-olds meeting the guidelines, but only $7.5 \%$ (6.3\% to $8.8 \%$ ) and $5.1 \%$ (3.7\% to $6.4 \%)$ of 12 - to 15-year-olds and 16- to 19-year-olds, respectively, meeting the guidelines. These results are corroborated by data from the 2013 YRBSS, in which $57.3 \%$ and $37.3 \%$ of high-school aged boys and girls, respectively, self-reported achieving $60 \mathrm{~min} /$ day of PA on at least 5 of the last 7 days. ${ }^{8}$ Thus, given the low national prevalence of achieving PA guidelines by U.S. children and youth using objective monitoring, coupled with evidence of age and gender disparities, a grade of $D$ - was assigned to this indicator.

\section{Sedentary Behaviors: $D$ -}

There are currently no quantitative guidelines for limiting overall sedentary behavior in children and youth in the U.S. Thus, the Committee relied on estimates and recommendations for screen time as the primary indicator of Sedentary Behavior. The National Heart, Lung and Blood Institute and the American Academy of Pediatrics recommend no more than 2 hours of screen time per day for children and youth. ${ }^{9,10}$ The primary data source for screen time was the 2013-2014 NHANES public-use dataset. A total of 37.2\% (34.2\% to $40.3 \%$ ) of U.S. children and youth 2 to 19 years of age are currently meeting these screen time guidelines. However, the prevalence of meeting guidelines declines across age groups: 2 to 5 years $(47.1 \% ; 42.6 \%$ to $51.6 \%)$; 6 to 11 years $(39.4 \% ; 35.0 \%$ to $43.7 \%)$, and 12 to 19 years $(30.8 \% ; 26.2 \%$ to $35.4 \%)$. Further, race/ethnic disparities were observed in screen time estimates. Non-Hispanic Asian (46.8\%; 39.1\% to 54.4\%) and non-Hispanic white $(39.6 \% ; 34.9 \%$ to $44.4 \%)$ children and youth have the highest prevalence of meeting screen time guidelines followed by Hispanic/ Mexican American (35.7\%; 30.9\% to 40.5\%) and Non-Hispanic black $(26.7 \% ; 23.2 \%$ to $30.3 \%)$ children and youth. Given the low prevalence of meeting screen time guidelines and the presence of age and race/ethnic disparities, a grade of $D$-was assigned for sedentary behavior.

\section{Active Transportation: $\boldsymbol{F}$}

The Committee maintained the primary indicator for Active Transportation as the percentage of U.S. children and youth who usually walk or bike to school, as measured by the NHTS. No new NHTS data have been released on active transportation since 2009, so the estimate of the proportion of children who usually walk or bike to school remains at $12.7 \% .{ }^{11}$ Two new secondary data sources were added for the 2016 Report Card. At the school level, the 2014 School Health Policies and Practices Study (SHPPS) reported that in 61.5\% of schools, $10 \%$ or less of the students walk or bike to school in the morning, and in $61.7 \%$ of schools, $10 \%$ or less of students walk or bike to a destination (including home) after school. ${ }^{12}$ Second, the 2012 NNYFS asked children "Do you walk or bike to get to and from places?", and based on our analysis of the dataset, $52.2 \%$ of
12- to 15-year-olds responded positively. The grade of $F$ assigned for Active Transportation reflects the low overall prevalence of this behavior among children and youth.

\section{Organized Sport Participation: C-}

Organized youth sports have a long, rich history in the United States. There has been a long-term trend of increasing high school sport participation since the early 1970s; however, a gender gap where a greater number of boys than girls participate continues. ${ }^{13}$ The primary indicator for organized sport participation is the proportion of U.S. high school students participating on at least 1 school or community sports team, as reported by youth through the YRBSS. In the 2013 YRBSS, $54.0 \%$ of high school students reported participating on at least 1 sports team. ${ }^{8}$ However, there are significant gender disparities, as $59.6 \%$ of boys reported participating in sports as compared with $48.5 \%$ of girls. ${ }^{8}$ A grade of $C$ - was assigned for Organized Sport Participation based on the relatively low overall prevalence and the existence of a gender disparity.

\section{Active Play: INC}

The Committee recognizes the importance of promoting active play among children and youth as one opportunity for PA. The indicator is the proportion of U.S. children and youth participating in daily unstructured, unorganized active play. However, there is currently a lack of nationally representative data to inform the selection of a grade for the 2016 Report Card, so an incomplete grade was assigned. One opportunity for active play is school recess. According to the 2014 SHPPS, more than $90 \%$ of schools offer recess to children from kindergarten through the fifth grade; however, this figure drops to $34 \%$ in the 6 th grade. ${ }^{12}$ On a positive note, in $93.1 \%$ of elementary schools, the format of recess allows for children to engage in unstructured free play. ${ }^{12}$

\section{Health-related Fitness: $D$}

Health-related fitness refers to those components of physical fitness that are affected by PA and are related to health status. ${ }^{14}$ In general, there are 5 main components of Health-related Fitness, including cardiorespiratory, morphological, muscular, motor, and metabolic fitness. The primary indicator for the 2016 Report Card was the proportion of U.S. youth meeting cardiorespiratory fitness standards. The primary data source was the NNYFS, and the benchmark was the proportion of youth who were in the Healthy Fitness Zone (HFZ) for cardiorespiratory fitness using the FITNESSGRAM criteria. ${ }^{15}$ Among 12- to 15-year-olds participating in the 2012 NNYFS, $42.3 \%$ (95\% CI: $36.3 \%$ to $48.3 \%$ ) were in the HFZ for cardiorespiratory fitness. Further, there were disparities by gender and race/ethnicity. Significantly fewer girls $(33.9 \% ; 27.5 \%$ to $40.2 \%)$ as compared with boys $(50.4 \% ; 42.7 \%$ to $58.2 \%)$ were in the HFZ, and there were differences across race/ethnicity as well, with $37.6 \%(22.0 \%$ to $53.3 \%$ ) of non-Hispanic black, $42.7 \%$ (32.1 to 53.3) of Hispanic/ Mexican American, and 44.2\% (37.0\% to 51.4\%) of non-Hispanic white youth meeting the HFZ criterion.

In addition to the primary indicator of cardiorespiratory fitness, several secondary indicators of health-related fitness were also evaluated, including muscular fitness, morphological fitness and metabolic fitness. Data from the 2012 NNYFS indicate that 
$51.7 \%$ of youth 6 to 15 years of age are in the HFZ for pull-ups, with $47.4 \%$ (41.7\% to $53.0 \%$ ) of girls and $55.8 \%$ (48.0\% to $63.7 \%$ ) of boys meeting the HFZ standard. The most recent report from 2011-2012 NHANES shows the prevalence of obesity in 2 to 19 year old children was $16.9 \%$ (95\% CI: $14.9 \%$ to $19.2 \%$ ), placing them in the FITNESSGRAM Health Risk zone. ${ }^{16}$ Further, a recent analysis of data from NHANES (1999-2012) estimated the prevalence of metabolic syndrome (ie, clustering of 3 or more risk factors including high BMI, high blood glucose, low HDL-cholesterol, high triglycerides, and high blood pressure $)^{17}$ in 12 - to 19 -yearold adolescents was $9.8 \%$, and the prevalence was higher in boys $(10.9 \%)$ than in girls $(6.3 \%){ }^{17}$

Overall, health-related fitness received a grade of $D$ to reflect the low proportion of children in the HFZ for cardiorespiratory fitness and to acknowledge the observed gender and race/ethnic disparities.

\section{Family and Peers: INC}

The Committee recognizes the important role that family and peers can play in promoting PA among children and youth. A primary indicator was developed for the 2016 Report Card, which is the proportion of U.S. parents or guardians and peers who provide social and instrumental support for children's PA. Unfortunately, there are currently no nationally representative data available to inform the assignment of a grade for this indicator. Thus, assessing family and peer support for PA is highlighted as a priority for future surveillance efforts. In an effort to provide some indirect evidence of parents/ guardians as role models for PA, a subset of adults (20-60 years of age) from the 2012-2013 NHANES dataset with children 17 years of age or younger living in their household was identified. Their weekly self-reported levels of MVPA were computed as [(weekly minutes of vigorous activity $\times 2$ ) + (weekly minutes of moderate activity)] to estimate the prevalence of adults meeting the guidelines of 150 minutes/week of MVPA. ${ }^{2}$ The results showed that $45.0 \%$ (95\% CI: $41.1 \%$ to $48.8 \%$ ) of adults without children living in the household met the PA guidelines compared with $39.2 \%$ (95\% CI: $35.9 \%$ to $42.4 \%$ ) of adults with children living in the household.

\section{School: $D+$}

Schools represent an environment that has the potential to influence the PA and sedentary behavior of most children and youth. Physical education is the cornerstone of any Comprehensive School Physical Activity Program, and the grade for this indicator was based on the prevalence of high school students who attended at least 1 physical education class per week. The Committee acknowledges that this benchmark sets a low bar, especially when compared with the current PA recommendations for children and youth of achieving 60 minutes per day of PA. ${ }^{2}$ Data from the 2013 YRBSS indicate that $48.0 \%$ of high school students attended at least 1 physical education class in the previous week. ${ }^{8}$ In addition, participation in physical education is higher in boys (53.3\%) compared with girls (42.8\%), and it decreases across the high school years. ${ }^{8}$ Indeed, data from the 2014 SHPPS indicate that the percentage of schools requiring physical education ranges from $43 \%$ to $47 \%$ from kindergarten to the fifth grade, then decreases in a graded fashion to the eleventh and twelfth grades where the percentage is below 9\%. ${ }^{12}$ As mentioned above, schools can provide significant opportunities for PA beyond physical education. The percentage of secondary schools that have established and implemented a Comprehensive School Physical Activity Program, however, ranges from $0 \%$ to $10.2 \%$ across the surveyed states, with a median of $3.1 \% .{ }^{18}$ The grade assigned for the school indicator was a $D+$ and reflects the low prevalence of youth attending physical education, gender and age disparities in physical education, and the current low prevalence of Comprehensive School Physical Activity Programs.

\section{Community and Built Environment: $B$ -}

To remain consistent with the 2014 Report Card, the Committee chose the primary indicator as the proportion of children and youth living in neighborhoods with at least 1 park or playground area. The primary data source was the 2011-2012 NSCH, which indicated that $84.6 \%$ of children 12 years old and younger lived in neighborhoods with at least 1 park or playground area based on parental report. ${ }^{19}$ Further, data from the 2011-2012 NSCH also showed that $86.6 \%$ of children lived in "safe" neighborhoods; however, there are significant disparities related to race/ethnicity and socioeconomic status. For example, $77.2 \%$ and $77 \%$ of Hispanic and African American children, respectively, reported living in safe neighborhoods, compared with $93.2 \%$ of white children. ${ }^{19}$ The relatively high level of access to parks and playgrounds led the Committee to assign a high grade for the community and built environment, which was downgraded to a $B$ - due to the existence of disparities. There are many aspects to the built environment, and it is important to note that the primary indicator taps into only 1 aspect of the built environment.

\section{Government Strategies and Investments: INC}

Local, state, and federal governments have an important role to play in the promotion of PA among children and youth. Policies, strategies and investments that increase opportunities for PA have the potential to significantly impact population health..$^{20}$ The U.S. federal government has initiated several programs that are aimed at improving PA levels in the population, as described in the 2014 Report Card. ${ }^{7}$ The 2016 Report Card focused on governmental investments that support Comprehensive School Physical Activity Programs. However, there are insufficient data currently available to establish a robust benchmark to track progress in government strategies and investments. Therefore the Committee decided to assign a grade of incomplete for this indicator.

\section{Discussion}

\section{Overall Physical Activity}

The grade for Overall Physical Activity on the 2016 Report Card remains consistent with the 2014 Report Card at a $D$-. The low grade reflects the finding that the majority of children and youth in the U.S. do not meet PA recommendations (78.4\%) based on objective monitoring and the existence of age and gender differences in PA participation. Boys are more active than girls, and there is a decline in PA levels with advancing age onto adolescence. These results are consistent with global trends, which suggest that approximately $80 \%$ of adolescents worldwide are not obtaining the recommended levels of PA. ${ }^{4}$ Given the positive associations between PA and many health parameters during childhood, ${ }^{21}$ and the moderate tracking for PA between childhood and older ages, ${ }^{22}$ the promotion of PA among children and youth remains a public health priority.

\section{Sedentary Behaviors}

The Sedentary Behavior Research Network has defined sedentary behaviors as "any waking behavior characterized by an energy 
expenditure $\leq 1.5$ metabolic equivalents (METs) while in a sitting or reclining posture." 23 Several epidemiological studies have identified associations between sedentary behavior and health indicators in children, ${ }^{24}$ as well as between sedentary behavior and chronic disease incidence and premature mortality in adults. ${ }^{25,26}$ However, there is currently insufficient evidence to develop quantitative guidelines for total sedentary behavior in children or adults. The Committee chose to grade sedentary behavior based on screen time, which is a prominent sedentary behavior of children and youth. Our analysis of the 2013-2014 NHANES indicated that only $37.2 \%$ of U.S. children and youth 2 to 19 years of age are currently meeting screen time guidelines ( $<2$ hours per day). This estimate is lower than the estimate in the 2014 Report Card (53.5\%) which was based on an analysis of the 2009-2010 NHANES by Fakhouri et al. ${ }^{27}$ The estimates differ mainly due to the differences in the age ranges of the samples (2-19 years in the current study and 6-11 years in the Fakhouri study). Given this new information, and the presence of significant age, gender, and ethnic/race disparities, the grade for Sedentary Behavior was lowered from a $D$ on the 2014 Report Card to a $D$ - on the 2016 Report Card.

\section{Active Transportation}

The Active Transportation indicator received a grade of $F$, the lowest grade on the 2016 Report Card. The grade is unchanged since the 2014 Report Card, as no new data were available from the NHTS. The most recent data available are from the 2009 NHTS and the data showed that $12.7 \%$ of children and youth use active transportation (walking or biking) to travel to school, a decrease from $47.7 \%$ in $1969 .{ }^{11}$ The results of a recent study among 9- to 11-year-old children from 12 countries reinforce the notion that children who engage in active transportation are more physically active. ${ }^{28}$ On average, children who actively commuted to school accumulated 6.0 (95\% CI: 4.7 to 7.3 ) more minutes of MVPA on weekdays compared with those who used a passive means of transportation. ${ }^{28}$ Further, an analysis from the same study demonstrated that children who actively commuted to school were less likely to be obese (OR $=0.72 ; 95 \% \mathrm{CI}$ : 0.60 to 0.87$)$ compare with children who reported motorized travel to school. ${ }^{29}$ The grade of $F$ for Active Transportation indicates a great need to provide greater opportunities for children to safely walk and bicycle to and from their schools and other destinations.

\section{Organized Sport Participation}

Organized Sport Participation represents an important outlet for PA energy expenditure for children and youth. ${ }^{30}$ The grade for this indicator remained unchanged from the 2014 Report Card at $C$ - despite new data on the topic. The grade is based on the finding that approximately half of U.S. youth participated on at least 1 organized school or community sports team, and the prevalence was lower among girls compared with boys. This grade is encouraging; however, there is a continued need to provide opportunities for both boys and girls to participate in organized youth sports. A significant gender gap still exists in organized youth sports participation, so programs that encourage the participation of girls are particularly relevant.

\section{Active Play}

Unorganized play is one opportunity for children to be physically active. There is some evidence that children may sometimes be more active during free play when adults (parent, coach, etc.) are not directly leading activities compared with organized events. ${ }^{31}$ Further, a recent review concluded that children who spend more time outdoors are more likely to be physically active. ${ }^{32}$ The Committee acknowledges that active play is an important outlet for children to be active in fun, safe environments. However, the incomplete grades on the 2016 Report Card as well as the 2014 Report Card ${ }^{7}$ represent a lack of nationally representative data assessing how much time children and youth in the U.S. spend engaging in active play. This is an important area for future national surveillance efforts.

\section{Health-related Fitness}

Due to the release of new national data from the 2012 NNYFS, the Committee was able to provide a grade for health-related fitness for the 2016 Report Card. This indicator had previously received a grade of INC on the 2014 Report Card due to a lack of nationally representative data. The grade of $D$ reflects the finding of $42.3 \%$ of 12- to 15-year-old youth that are in the Healthy Fitness Zone of the FITNESSGRAM criteria for cardiorespiratory fitness. Further, analysis of secondary indicators that reflect other components of health-related fitness (ie, morphological, muscular, metabolic) also demonstrate poor overall fitness and health of U.S. children and youth. The lack of temporal fitness data on representative samples of the U.S. population makes the interpretation of time trends difficult; however, a global analysis of secular changes in aerobic fitness from 27 countries demonstrated overall decreases since about $1970 .{ }^{33}$ The continued surveillance of objective measurements of physical fitness of US children and youth is a public health priority.

\section{Family and Peers}

The Family and Peers indicator received a grade of $I N C$ on both the 2016 Report Card and the 2014 Report Card. The Committee acknowledges the influence of family and peers on children's PA; however, there is currently a lack of nationally representative data on this topic to inform the assignment of a grade.

\section{School}

The Committee acknowledges the importance of implementing Comprehensive School Physical Activity Programs as a means to improve opportunities for PA among children and youth; however, given the lack of regular surveillance data on this topic, we chose to retain participation in physical education as the indicator for the 2016 Report Card. Physical education is the foundation of a Comprehensive School Physical Activity Program, and existing national surveillance systems track participation on a regular basis. The grade for the School indicator decreased from $C$ - on the 2014 Report Card to $D+$ on the 2016 Report Card. Overall, the prevalence of attending at least 1 physical education class in an average week decreased slightly among high school students from 51.8\% to $48.0 \%$ between the 2011 YRBSS and the 2013 YRBSS. $^{8}$ However, significantly more males were attending physical education than girls, and attendance decreased significantly across advancing school grades. Initial results from the 2014 School Health Profiles Survey indicate that the percentage of secondary schools that have established and implemented a Comprehensive School Physical Activity Program was only $3.1 \%{ }^{18}$ however, the Committee will track changes in this indicator over time. 


\section{Community and Built Environment}

The grade for Community and the Built Environment remains unchanged from the 2014 Report Card at a $B$ - given that no new data were available to inform a change to the previous grade. As in the 2014 Report Card, the grade was assigned based only on the "presence" of a park or playground in a child's neighborhood rather than the quality of the infrastructure or the frequency of its use. Based on an analysis of assigned grades from 15 countries participating the 2014 Report Card initiative, ${ }^{34}$ there was a significant negative correlation (-0.69) between the grades for Overall Physical Activity and for Community and Built Environment, ${ }^{35}$ suggesting that the presence of infrastructure doesn't necessarily translate into higher levels of PA. Further national surveillance data are required to better inform a more comprehensive assessment of the community and built environment related to PA.

\section{Government Strategies and Investments}

Local, state, and federal governments have an important role to play in PA promotion. Multilevel intervention strategies that include public policy may help communities to achieve behavior changes, especially as they relate to PA. ${ }^{20}$ Although the Committee considers progress on policy and investments imperative to improving population levels of PA, insufficient data were available to establish a benchmark and assign a grade this year. Given the increasing emphasis on the importance of Comprehensive School Physical Activity Programs in recent years, the Committee decided to highlight some initiatives that support these programs as well as providing support for children with disabilities:

- The CDC's State Public Health Actions Program ${ }^{36}$ supports efforts nationwide to reduce the risk factors associated with childhood and adult obesity, diabetes, heart disease, and stroke. Specifically for physical education/PA, CDC currently funds all 50 states and the District of Columbia to support districts and schools in implementing 2 components of a Comprehensive School Physical Activity Program-physical education and recess (PA during school). CDC also funds 32 states to support districts and schools with an in-depth process of developing, implementing, and evaluating Comprehensive School Physical Activity Programs

- Let's Move! Active Schools ${ }^{37}$ is a national initiative that equips $\mathrm{K}-12$ schools with the resources, tools, professional development, funding opportunities, and technical assistance to create an active school environment where PA is integrated before, during and after school for at least 60 minutes every day

- The Presidential Youth Fitness Program ${ }^{38}$ addresses physical education, which is the foundational component of Comprehensive School Physical Activity Programs. The Presidential Youth Fitness Program helps schools achieve excellence in physical education through quality fitness education and assessment practices

- I Can Do It, You Can Do It (ICDI) ${ }^{39}$ is an effort on the part of the federal government to promote PA participation among children with disabilities, a group that appears to be at disproportionate risk for inactivity. ICDI is a mentoring program that uses an individualized approach to encourage regular PA and good nutrition for children and adults with disabilities.

These programs highlight the increasing interest in supporting Comprehensive School Physical Activity Program and increasing opportunities for children with disabilities. However, there is a need to increase the capacity of each state to implement these programs.

\section{Strengths and Limitations}

Major strengths of the 2016 Report Card include the use of nationally representative data to inform the assignment of the grades, the use of a quantitative grading rubric in both 2014 and 2016, the identification of a single primary data point for each indicator, and a diverse Report Card Research Advisory Committee with representation from across the country and from different disciplines. The grades are based on the best available data, but there are significant surveillance gaps, as 3 of the 10 indicators could not be graded. Further, some of the data are several years old, making it difficult to make inferences about recent trends and current status. Currently, there is a lack of nationally representative data on instrumental and social support for PA from family and peers. There is also a lack of data on how much time children spend in active play. The report card would benefit from the incorporation of these constructs into existing surveillance systems. A grade was also not assigned for Government Strategies and Investments. This is an important indicator, but data on these factors are difficult to generate, making it challenging to establish a benchmark for this indicator.

\section{Conclusion}

The poor grades on the 2016 U.S. Report Card suggest that more work is required to provide opportunities for children to be physically active. Further, the observed disparities indicate that special attention should be given to some subgroups of the population, such as girls, minorities, and those from lower socioeconomic status households, when implementing PA promotion strategies.

\section{Acknowledgments}

The authors thank the following individuals for their contributions to the 2016 United States Report Card: Shannon Michael, Centers for Disease Control and Prevention, and Emily Mire, Pennington Biomedical Research Center. Support for development of the 2016 U.S. Report Card was provided by the following National Physical Activity Plan Alliance Organizational Partners: SHAPE America, American Council on Exercise, and American Academy of Pediatrics.

\section{References}

1. Lee IM, Shiroma EJ, Lobelo F, et al. Effect of physical inactivity on major non-communicable diseases worldwide: an analysis of burden of disease and life expectancy. Lancet. 2012;380(9838):219-229. PubMed doi:10.1016/S0140-6736(12)61031-9

2. US Department of Health and Human Services. 2008 Physical Activity Guidelines for Americans. US Department of Health and Human Services, Centers for Disease Control and Prevention; 2008.

3. World Health Organization. Global Recommendations on Physical Activity for Health. Geneva, Switzerland: World Health Organization; 2010.

4. Hallal PC, Andersen LB, Bull FC, et al. Global physical activity levels: surveillance progress, pitfalls, and prospects. Lancet. 2012;380(9838):247-257. PubMed doi:10.1016/S01406736(12)60646-1

5. Troiano RP, Berrigan D, Dodd KW, Masse LC, Tilert T, McDowell M. Physical activity in the United States measured by accelerometer. 
Med Sci Sports Exerc. 2008;40(1):181-188. PubMed doi:10.1249/ mss.0b013e31815a51b3

6. Fakhouri TH, Hughes JP, Burt VL, Song M, Fulton JE, Ogden CL. Physical Activity in U.S. Youth Aged 12-15 Years, 2012. NCHS Data Brief, No. 141. Hyattsville, MD: National Center for Health Statistics; 2014.

7. Dentro KN, Beals K, Crouter S, et al. Results from the United States' 2014 report card on physical activity for children and youth. J Phys Act Health. 2014;11(Suppl. 1):S105-S125. PubMed doi:10.1123/ jpah.2014-0184

8. Centers for Disease Control and Prevention (CDC). 1991-2015 High School Youth Risk Behavior Survey Data. http://nccd.cdc.gov/ youthonline/. Accessed on July 1, 20162016.

9. American Academy of Pediatrics Council on Communications and Media. Policy statement—children, adolescents, obesity and the media. Pediatrics. 2011;128:201-208. PubMed doi:10.1542/ peds.2011-1066

10. The Expert Panel. Expert panel on integrated guidelines for cardiovascular health and risk reduction in children and adolescents: summary report. Pediatrics. 2011;128(Suppl. 5):S213-S256. PubMed doi:10.1542/peds.2009-2107C

11. Mcdonald MC, Brown AL, Marchetti LM, Pedroso MSUS. school travel, 2009: An assessment of trends. Am J Prev Med. 2011;41:146151. PubMed doi:10.1016/j.amepre.2011.04.006

12. US Department of Health and Human Services, Centers for Disease Control and Prevention. Results from the School Health Policies and Practices Study 2014. US Department of Health and Human Services, Centers for Disease Control and Prevention; 2015.

13. National Federation of State High School Associations. 2014-15 High School Athletics Participation Survey. http://www.nfhs.org/. Accessed August 12, 20161.

14. Bouchard C, Shephard RJ. Physical activity, fitness and health: The model and key concepts. In: Bouchard C, Shephard RJ, Stephens T, eds. Physical Activity, Fitness and Health. Champaign, IL: Human Kinetics; 1994:77-88. doi:10.1249/00005768-199401000-00024

15. Plowman SA, Meredith MD, eds. FitnessGram/ActivityGram Reference Guide. Dallas, TX: The Cooper Institute; 2013.

16. Ogden CL, Carroll MD, Kit BK, Flegal KM. Prevalence of childhood and adult obesity in the United States, 2011-2012. JAMA. 2014;311(8):806-814. PubMed doi:10.1001/jama.2014.732

17. Lee AM, Gurka MJ, DeBoer MD. Trends in metabolic syndrome severity and lifestyle factors among adolescents. Pediatrics. 2016;137(3):19. PubMed doi:10.1542/peds.2015-3177

18. Demissie Z, Brener ND, McManus T, Shanklin SL, Hawkins J, Kann L. School Health Profiles 2014: Characteristics of Health Programs among Secondary Schools. US Department of Health and Human Services, Centers for Disease Control and Prevention; 2015.

19. National Survey of Children's Health. NSCH 2011/2012 Data Query from the Child and Adolescent Health Measurement Initiative. Data Resource Center for Child and Adolescent Health website. www. childhealthdata.org. Accessed October 31, 2016.

20. Sallis JF, Cervero RB, Ascher W, Henderson KA, Kraft MK, Kerr J. An ecological approach to creating active living communities. Annu Rev Public Health. 2006;27:297-322. PubMed doi:10.1146/annurev. publhealth.27.021405.102100

21. Janssen I, LeBlanc AG. Systematic review of the health benefits of physical activity and fitness in school-aged children and youth. Int $J$ Behav Nutr Phys Act. 2010;7:40. PubMed doi:10.1186/1479-58687-40

22. Malina RM. Tracking of physical activity and physical fitness across the lifespan. Res Q Exerc Sport. 1996;67:S48-S57. PubMed doi:10. 1080/02701367.1996.10608853
23. Sedentary Behaviour Research Network. Letter to the Editor: Standardized use of the terms "sedentary" and "sedentary behaviours". Appl Physiol Nutr Metab. 2012;37:540-542.

24. Tremblay MS, LeBlanc AG, Kho ME, et al. Systematic review of sedentary behaviour and health indicators in school-aged children and youth. Int J Behav Nutr Phys Act. 2011;8:98. PubMed doi:10.1186/1479-5868-8-98

25. Thorp AA, Owen N, Neuhaus M, Dunstan DW. Sedentary behaviors and subsequent health outcomes in adults: a systematic review of longitudinal studies, 1996-2011. Am J Prev Med. 2011;41(2):207-215. PubMed doi:10.1016/j.amepre.2011.05.004

26. Proper KI, Singh AS, van Mechelen W, Chinapaw MJ. Sedentary behaviors and health outcomes among adults: a systematic review of prospective studies. Am J Prev Med. 2011;40(2):174-182. PubMed doi:10.1016/j.amepre.2010.10.015

27. Fakhouri TH, Hughes JP, Brody DJ, Kit BK, Ogden CL. Physical activity and screen-time viewing among elementary school-aged children in the United States from 2009 to 2010. JAMA Pediatr. 2013;167(3):223-229. PubMed doi:10.1001/2013.jamapediatrics.122

28. Denstel KD, Broyles ST, Larouche R, et al. Active school transport and weekday physical activity in 9-11 year old children from 12 countries. Int J Obes Suppl. 2015;5(2):S100-S106. PubMed doi:10.1038/ ijosup.2015.26

29. Sarmiento OL, Lemoine P, Gonzalez SA, et al. Relationships between active school transport and adiposity indicators in school age children from low-, middle- and high-income countries. Int J Obes Suppl. 2015;5(2):S107-S114. PubMed doi:10.1038/ijosup.2015.27

30. Katzmarzyk PT, Malina RM. Contribution of organized sports participation to estimated daily energy expenditure in youth. Pediatr Exerc Sci. 1998;10:378-386. doi:10.1123/pes.10.4.378

31. Trost SG, Rosenkranz RR, Dzewaltowski D. Physical activity levels among children attending after-school programs. Med Sci Sports Exerc. 2008;40:622-629. PubMed doi:10.1249/MSS.0b013e318161eaa5

32. Gray C, Gibbons R, Larouche R, et al. What is the relationship between outdoor time and physical activity, sedentary behaviour, and physical fitness in children? A systematic review. Int $J$ Environ Res Public Health. 2015;12(6):6455-6474. PubMed doi:10.3390/ ijerph120606455

33. Tomkinson GR, Olds TS. Secular changes in pediatric aerobic fitness test performance: the global picture. Med Sport Sci. 2007;50:46-66. PubMed doi:10.1159/000101075

34. Tremblay MS, Gray CE, Akinroye K, et al. Physical activity of children: a global matrix of grades comparing 15 countries. J Phys Act Health. 2014;11(Suppl. 1):S113-S125. PubMed doi:10.1123/ jpah.2014-0177

35. Katzmarzyk PT. Increasing global research capacity in physical activity for children and youth. Res Exerc Epidemiol. 2014;16:71-75.

36. National Center for Chronic Disease Prevention and Health Promotion. State Public Health Actions to Prevent and Control Diabetes, Heart Disease, Obesity and Associated Risk Factors and Promote School Health (DP13-1305) (http://www.cdc.gov/chronicdisease/about/statepublic-health-actions.htm). Atlanta, GA: Centers for Disease Control and Prevention; 2016.

37. Let's Move Active Schools. Let's Move Active Schools. 2016. http:// www.letsmoveschools.org/about/. Accessed October 31, 2016.

38. Presidential Youth Fitness Program. Presidential Youth Fitness Program. 2016. http://www.pyfp.org/. Accessed October 31, 2016.

39. Can Do It I. You Can Do It. 2016. www.fitness.gov/participate-inprograms/i-can-do-it-you-can-do-it/. Accessed October 31, 2016. 